par una distribución normal (o log-normal) con media y desviación estándar estimada según observaciones históricas.

Ejemplo crudo: la caída de las acciones de EE.UU. El 19 de octubre de 1987 era tan improbable (imás de 20 desviaciones estándar!), que un modelo convencional no habría anticipado que ocurriera antes de 20.000 millones de años. (Sí. Leyó bien: veinte mil millones de años). Si hablamos de los 60 dias de caídas que siguen al 19 de septiembre de 2008, también nos cansamos de contar ceros en los billonésimos de probabilidad que ocurriera lo que ocurrió.

Los modelos más asentados tratan las crisis como rarezas (outliers) pero ocurre que es entonces y no en la "normalidad" cuando se juegan todo quienes no pueden esperar recuperaciones. Fijese usted que solo diez días extremadamente "raros" explican la mitad de los retornos en la bolsa de los EE.UU. durante los últimos 50 años. ${ }^{5}$

Tienen razón entonces quienes proclaman el fin de la economía de casino, aunque por razones completamente distintas a las que ellos creen. Un modelo probabilistico que gobierne los resultados de un juego de azar es enteramente válido para sucesos o experimentos controlados (la ruleta, el cachipún). En finanzas, dicho modelo no sirve para eventos como los precios de las acciones, commodities u otros de alto impacto cuantitativo. Consecuentemente, los entusiastas del VaR (Comité de Basilea incluido) o del enfoque CAPM, estarian subestimando los riesgos.

¿Qué existe a cambio del modelo tradicional tipo campana de Gauss?

La verdad, no mucho. Una excepción notable son los modelos de Mandelbrot, que intentan lidiar con lo que ese autor llama "la aleatoriedad salvaje". Él postula que los retornos de inversiones exhiben valores que no pueden conformar una distribución "normal" y que, por tanto, la desviación estándar deja de ser un indicador confiable para evaluar riesgo. ${ }^{6}$
Mandelbrot ofrece las "leyes de potencia", según las cuales la probabilidad de pérdidas más y más grandes declina linealmente: mucho más lento de lo que supone la popular distribución "normal" ?

En resumen, el hecho empírico es que ni el retorno ni el riesgo son fácilmente predecibles. El retorno no lo es porque los mercados son, a la larga, eficientes y el mero trading oportunista no permite a nadie rentar de manera persistente. El riesgo no es fácilmente cuantificable, porque los modelos más difundidos contienen un supuesto de normalidad que los hace especialmente limitados.

Bien harian muchas publicaciones de analistas financieros en advertir que sus predicciones, por plausibles que parezcan al sentido común o sensación ambiente, no tienen mayor valor predictivo que la conjetura que pueda hacer cualquier "no-experto".

La literatura lo prueba, la industria -iera que no!- lo calla.

${ }^{4}$ Para las citas de estudios empíricos sobre administración de carteras de bonos y acciones véase Foxley, Juan. ¿Para qué sirven los intermediarios de valores? Trend Management (por aparecer)

${ }^{5}$ TALEB, NASSIM: The Black Swan. Londres: Penguin, 2007.

${ }^{6}$ MANDELBROT, BENOIT y R. HUDSON, The (mis)

Behavior of Markets: A Fractal View of Risk, Ruin and Reward. Nueva York: Basic Books, 2004.

${ }^{7}$ Otras alternativas al enfoque media-varianza tradicional exploran distribuciones de probabilidad asimétrica y combinaciones de otros modelos que admiten saltos abruptos en los retornos. Ver por ejemplo, CAMPBELL, R. HARVEY y A. SIDDIQUE. Conditional Skewness in Asset Pricing Tests. Journal of Finance, (55): 1263 - 1295, 2000.

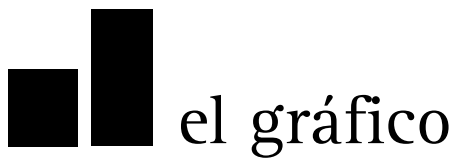

\section{" DÓLAR EN TIEMPOS DE CRISIS}

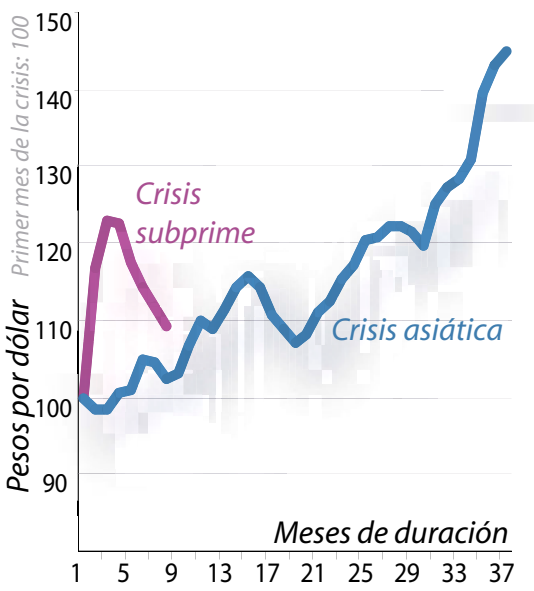

\section{Por Carlos García*}

Una de las incógnitas que enfrentará la economía chilena es cuál será la trayectoria del dólar. En la crisis asiática el peso se depreció fuertemente, lo que fue clave para estimular las exportaciones y salir adelante. Tres años después del inicio de la crisis asiática, se había depreciado en 45\%. Sin embargo, en la actual coyuntura, la evolución del dólar ha tomado otro camino: la política monetaria de la Reserva Federal de EE.UU. ha depreciado el dólar en todo el mundo. Entonces, ¿cómo enfrentaremos la crisis si el dólar no aumenta de valor?

La alternativa parece ser, hasta ahora, aumentar el gasto público para impulsar la demanda interna. ¿Pero será este proceso, liderado por el gobierno, eficiente? Será prioridad controlar la ejecución del gasto y que el programa de estímulo fiscal se cumpla a cabalidad. Si no, estaremos en el peor de los escenarios: estancamiento, falta de credibilidad de la política fiscal y una política monetaria con tasas de interés cercanas a cero.

* Profesor Facultad de Economía y Negocios, UAH. Ph.D. en Economía, UCLA. 